\title{
ConOMIC ONSULTANT
}

\section{Roman I. Ostapenko}

\section{Publishing work on the authority}

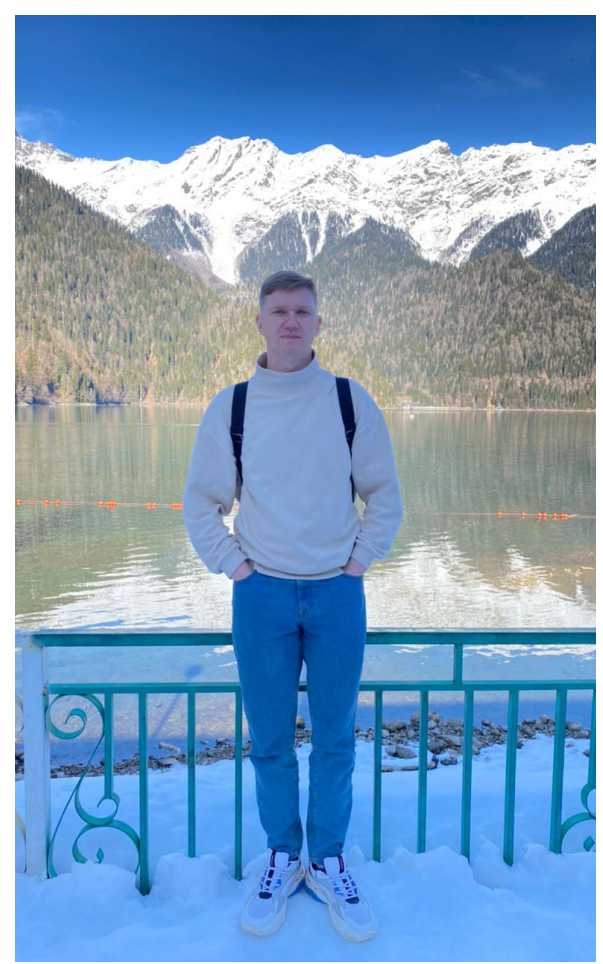

n a conversation with the
executive editor of a reputable periodical, I noticed that the journal "Economic Consultant", according to the financial model of Gold Open Access, publishes its articles in the open access, but at the same time charges the authors (or institutions) for publishing services*. In response, I heard the editor exclaim: "If our journal becomes paid, I will leave my job!" The authors are also dissatisfied with the need to pay for the publication, I quote: "I don't agree! I have never paid for my intellectual product, and I am not going to pay for it. I give it for free, and I consider the publication of my material as a fee for my work".

* Open access // Elsevier.com. Available at: https://www.elsevier.com/open-access (accessed 16 February)

\section{FOR CITATION}

Indeed, some institutions have their own journals, the publication of which is free for employees. However, this is possible because the work of proofreaders, reviewers, and employees of the printing house is paid by the scientific or educational organization itself. Young commercial publishers that do not have sponsorship have to cover their costs through payments from authors.

It should be noted that the absence of printed versions of journals does not in any way simplify publishing: electronic periodicals have additional expenses for maintaining the site, preparing data for uploading to bibliographic and information databases, etc.

With that, it is necessary to understand that the reflection of the results of specialists' research work in periodicals significantly increases the authority not only of the authors themselves but also of these publications.

A number of commercial periodicals take a hybrid approach to publishing. For example, some publications do not charge authors who "do credit to the journal". There are journals in which the authors act as free consultants, reviewers, thereby getting the opportunity to publish their own articles free of charge.

The rector of one of the higher education institutions, after another open day, said: "We used to choose, and now they choose us". Something similar is now observed in the publishing industry - there is a struggle between authors for publication in reputable periodicals, and young journals themselves have to fight for authors.

The journal "Economic Consultant" adheres to the financial model of Gold Open Access, which provides for payment by the authors for the services of preparing an article for publication. Almost the entire amount received from the author is spent on translating Russian-language articles into English, the rest - on typesetting, that is, the author understands what he is paying for. No fee is charged for authors of English-language articles in this case, we work according to the Platinum Open Access model since we do not charge either readers or authors ${ }^{* *}$.

Publishing activities under the open access model are funded by institutions, societies, using grants. In the absence of financial support, the publisher is forced to work for free - for the future, for credibility.

** Platinum Open Access // The Beilstein Journal of Organic Chemistry. Available at: https://www.beilstein-journals.org/bjoc/openAccess (accessed 16 February)

Ostapenko, R. I. (2021). Publishing work on the authority (Editorin-chief's column). Economic consultant, 33 (1), 4. doi: 10.46224/ ecoc.2021.1.1 